Earlier removal of the aortic cannula may have prevented this complication.

Thrombus formation, both microscopic and macroscopic, has the potential for disastrous complications in patients receiving antifibrinolytic therapy. The risk of thrombus formation may be increased with stasis of blood. We would therefore recommend early removal of intravascular catheters when antifibrinolytic therapy has been instituted.

\section{REFERENCES}

1. Harder MP, Eijsman L, Roozendaal KJ, van Oeveren W, Wildevuur RH: Aprotinin reduces intraoperative and postoperative blood loss in membrane oxygenator cardiopulmonary bypass. Ann Thorac Surg 1991;51:936-41.

2. Havel M., Teufelsbauer H, Knöbl P, Dalmatiner R, Jaksch P,
Zwölfer W, et al. Effect of intraoperative aprotinin administration on postoperative bleeding in patients undergoing cardiopulmonary bypass operation. J Thorac Cardiovasc Surg 1991;101:968-72.

3. Hardy JF, Desroaches J. Review article: Natural and synthetic antifibrinolytics in cardiac surgery. Can $\mathbf{J}$ Anaesth 1992;39: 353-65.

4. Bidstrup BP, Royston D, Sapsford RN, Taylor KM. Reduction in blood loss and blood use after cardiopulmonary bypass with high-dose aprotinin (Trasylol). J Thorac Cardiovasc Surg 1989;97:364-72.

5. Bohrer H, Fleischer F, Lang J, Vahl C. Early thrombus formation on pulmonary artery catheters in cardiac surgical patients receiving high dose aprotinin. J Cardiothorac Anesth 1990;4:222-6.

\title{
RECURRENT THROMBOSIS OF BIVENTRICULAR-SUPPORT DEVICES ASSOCIATED WITH ACCELERATED INTRAVASCULAR COAGULATION AND INCREASED HEPARIN REQUIREMENTS
}

George J. Despotis, MD, Vladimir Levine, MD, Alexander Alsoufiev, MD, Heinrich Joist, MD, PhD, Lawrence T. Goodnough, MD, and Michael Pasque, MD, St. Louis, Mo.

Thrombus formation in ventricular-assist devices has occurred despite apparently adequate anticoagulant therapy. The factors and mechanisms involved in the development of this potentially serious complication are poorly understood. We describe the case of a patient in whom multiple episodes of thrombosis developed in biventricular-support devices (BIVADs) used as a bridge to cardiac transplantation. These episodes were associated with accelerated intravascular coagulation and increased heparin requirements, which seemed to be favorably affected by administration of fresh-frozen plasma (FFP).

A 44-year-old white man came to our tertiary care institution for cardiac transplantation evaluation after a recent episode of congestive heart failure that was unresponsive to aggressive medical management. After an 8-year history of myocardial infarctions and progressive heart failure, he began a period of rapid deterioration 4 months before admission, at which time evaluation revealed endstage ischemic cardiomyopathy. Cardiac catheterization demonstrated global left ventricular hypokinesia with an ejection fraction of $7 \%$ and severe coronary artery dis-

From the Departments of Anesthesiology, Internal Medicine, Pathology, and Surgery, Washington University School of Medicine, and the Departments of Internal Medicine and Pathology, St. Louis University School of Medicine, St. Louis, Mo.

Supported in part by a research grant from ABIOMED Cardiovascular, Inc., Danvers, Mass.

Received for publication Aug. 7, 1995; accepted for publication Sept. 7, 1995.

J Thorac Cardiovase Surg 1996;112:538-40

Copyright (c) 1996 by Mosby-Year Book, Inc.

$0022-5223 / 96 \$ 5.00+0 \quad \mathbf{1 2 / 5 4} / \mathbf{6 9 2 5 4}$ ease; transthoracic echocardiography revealed moderately severe mitral and moderate tricuspid regurgitation. Previous management of his cardiac condition included inotropic support, afterload reduction, and diuresis. Laboratory evaluation showed elevated transaminase levels, reduced total protein level, reduced albumin level, and increased bilirubin level and prothrombin time, consistent with chronic, passive liver congestion.

On arrival, the patient was noted to be in severe congestive heart failure accompanied by tachycardia at 150 beats/min as a result of atrial flutter with a $2: 1$ conduction block. Initial treatment consisted of cardioversion to sinus rhythm followed by intravenous administration of nipride, dobutamine, and amrinone and subcutaneous injection of heparin (5000 U every 12 hours). The patient's condition worsened during the next several days, with development of cardiogenic shock (systolic blood pressure, 70 to $80 \mathrm{~mm} \mathrm{Hg}$; pulmonary artery wedge pressure, $38 \mathrm{~mm} \mathrm{Hg}$; cardiac index $<1.5$ ) despite large doses of dobutamine and amrinone necessitating bypass resuscitation on day 9 (Fig. 1). Subsequently, ABIOMED (ABIOMED Cardiovascular, Inc., Danvers, Mass.) biventricular support devices (BIVADs) were inserted as a bridge to transplantation. After insertion of the BIVADs, the patient had anticoagulation with a continuous infusion of heparin at 1800 to $2100 \mathrm{U} / \mathrm{hr}$ to maintain the celite activated clotting time (ACT) between 180 and 200 seconds. During days 9 through 19, a progressive increase in heparin requirements $(4000 \mathrm{U} / \mathrm{hr})$ was noted. On day 19 , clot formation in the BIVAD circuit necessitated emergency operative replacement of the BIVAD system (Fig. 1). Recurrent BIVAD thrombosis was noted on day 20 , necessitating a second replacement of the BIVAD system. In light of these events and a decrease in the platelet 


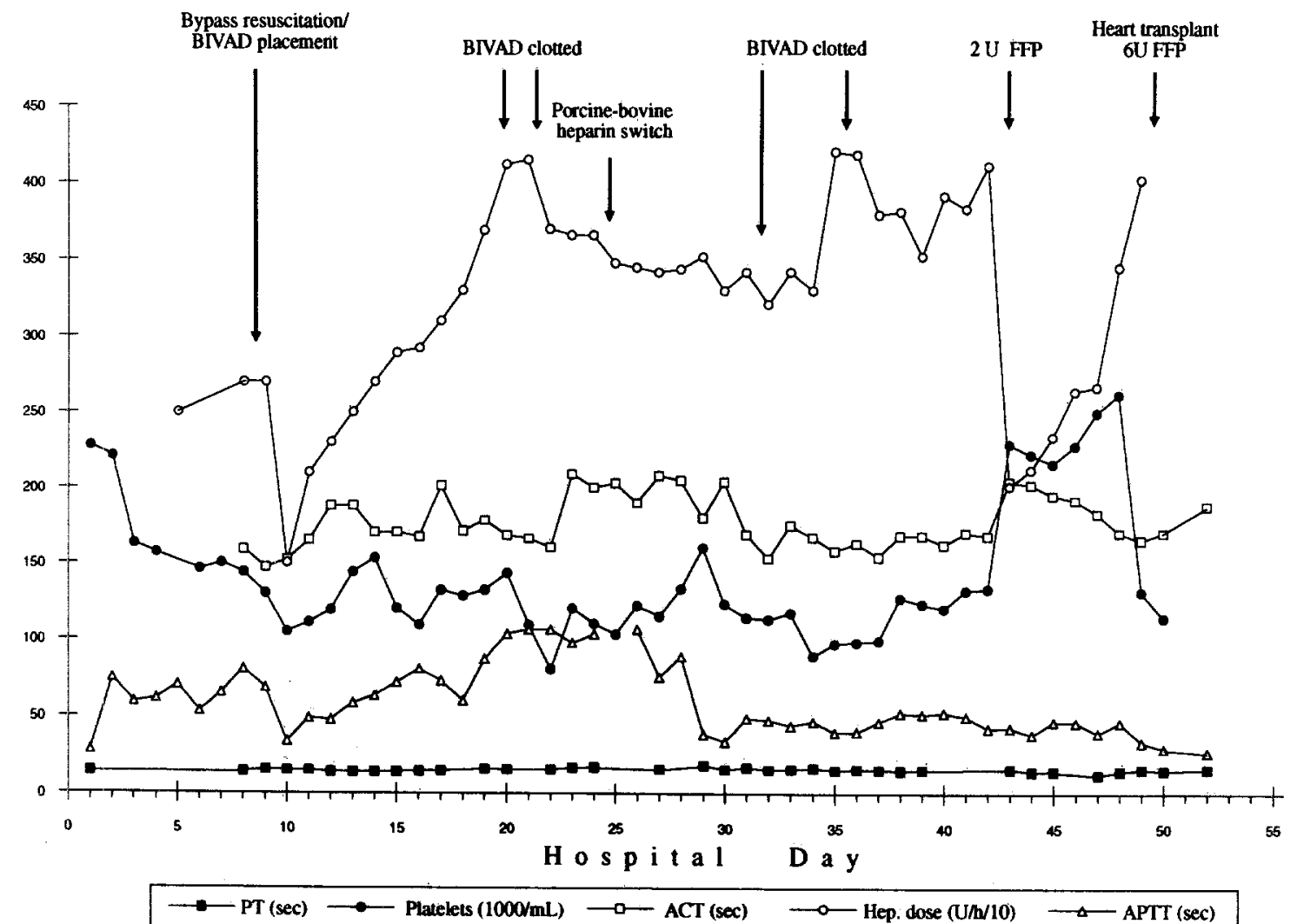

Fig. 1. Alteration in hemostatic system and heparin dose requirements in relationship to the clinical course of a patient with BIVADs inserted for heart failure caused by end-stage ischemic cardiomyopathy. Ordinate: prothrombin time $(P T)$ in seconds, average celite ACT in seconds, and average rate of heparin infusion in $\mathrm{U} / \mathrm{hr} / 10$ (Hep. dose), activated partial thromboplastin time (APTT) in seconds, and platelet count in $10^{3}$ cells $/ \mu$ l (Platelets).

count after operation from 230,000 to 68,000 cells $/ \mu 1$ (days 20 through 24), heparin-induced thrombocytopeniathrombosis was suspected and a change in heparin from porcine to bovine was made on day 24 . Heparin-induced thrombocytopenia-thrombosis was subsequently ruled out by negative results of a platelet serotonin release study. The BIVAD system was replaced for a third time on day 34 after visualization of clots in the circuit; this was also associated with an appreciable increase in heparin requirements. The persistently high heparin requirements ( $4000 \mathrm{U} / \mathrm{hr}$ ) prompted administration of $2 \mathrm{U}$ FFP on day 43. The FFP was associated with a $50 \%$ decrease in heparin dose requirements (Fig. 1). In view of this finding, informed consent was obtained and blood specimens were collected daily for a more detailed evaluation of the patient's coagulation status, including response to heparin as estimated with a heparin dose-ACT response slope (HDR slope) obtained by means of an automated bedside assay (HDR assay; Medtronic Hemo Tec, Parker, Colo.), and levels of antithrombin III, factor V, factor X, tissue factor pathway inhibitor, platelet counts, anti-factor $\mathrm{Xa}$ heparin concentration, protein $\mathrm{C}$, protein $\mathrm{S}$, fibrinopep: tide $A$, and prothrombin fragment 1.2. Factor $X$ and protein $\mathrm{C}$ and $\mathrm{S}$ concentrations were normal during this period. The results of the other assays obtained during days 44 through 57 are summarized in Fig. 2. Heparin requirements again progressively increased during days 44 through 48 , at which time the patient underwent cardiac transplantation. The patient had an unventful postoperative course and was discharged without neurologic deficits.

It is well established that extracorporeal circulation can induce complex hemostatic system abnormalities, in part mediated by activation of platelets, coagulation, and fibrinolysis with consumption of platelets and labile coagulation factors and sometimes associated with thrombosis. Heparin anticoagulation protocols are frequently used to prevent excessive hemostatic system activation and thrombosis. Heparin anticoagulation is routinely monitored with the ACT, values of which are maintained at approximately 200 seconds to minimize bleeding, a frequent complication of extracorporeal life support. ${ }^{1}$ Numerous variables can affect ACT measurements, ${ }^{2}$ however, and therapeutic ACT values do not guarantee suppression of excessive thrombin generation during extracorporeal circulation. ${ }^{3}$ Our evaluation indicates that the multiple thrombotic episodes in this patient may have been related to an underlying state of excessive hemostatic system activation, due at least in part to 


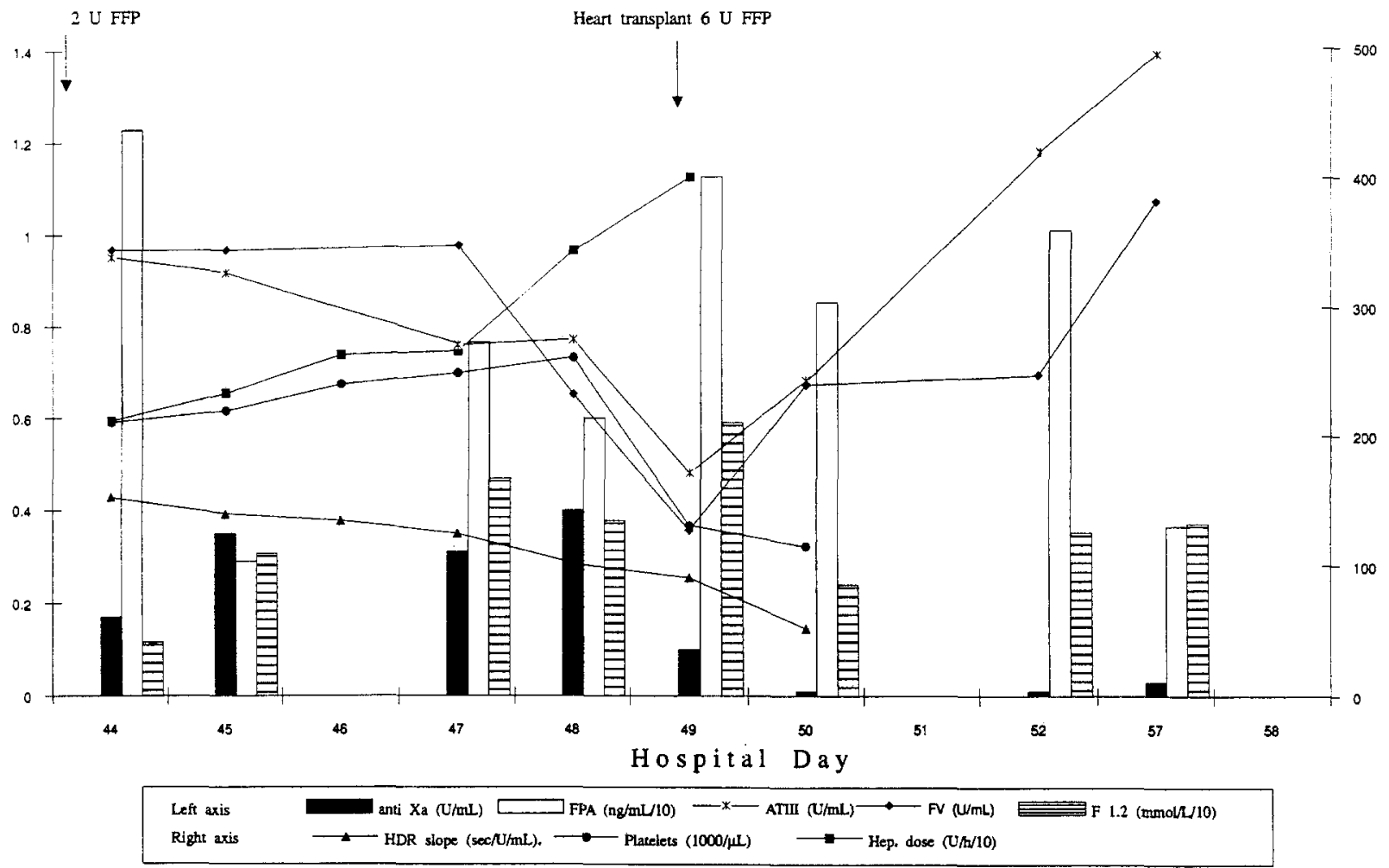

Fig. 2. Hematologic measurements during hospitalization days 44 through 57 after infusion of 2 U FFP for heparin resistance. Left ordinate: anti-factor Xa heparin concentration in $\mathrm{U} / \mathrm{ml}$ (anti-Xa), fibrinopeptide A in $\mathrm{ng} / \mathrm{ml} / 10(F P A)$, prothrombin fragment $1.2 \mathrm{in} \mathrm{mmol} / \mathrm{L} / 10$ (F1.2), antithrombin III in U/ml (ATIII), and factor $\mathrm{V}$ in $\mathrm{U} / \mathrm{m}(\mathrm{FV})$. Right ordinate: average rate of heparin infusion in $\mathrm{U} / \mathrm{hr} / 10$ (Hep. dose). HDR slope in sec/U/ml, and platelet count in $10^{3}$ cells/ $\mu$ l (Platelets).

inadequate anticoagulation as demonstrated by a dosetime association between increased heparin requirements and thrombotic events, (2) rapidly and markedly reduced heparin requirements after infusion of even relatively small amounts of FFP, and (3) progressive rises in prothrombin fragment 1.2 level, fibrinopeptide A level, and heparin requirements in conjunction with a fall in HDR slope and antithrombin III and factor V levels during days 44 through 48 . Increased heparin resistance as a result of reduced antithrombin III, previously described in cardiac surgical patients receiving heparin before operation, ${ }^{4}$ thus may result in progressive consumption coagulopathy even when ACT values are within the therapeutic range. Furthermore, patients with cardiomyopathy who require biventricular support have been noted to be at particularly high risk for thrombosis as a result of hypercoagulability. ${ }^{5}$ Further prospective studies are needed to determine more accurately the prevalence of abnormal bleeding and thrombosis with BIVADs, to determine the optimal therapeutic range for heparin and coumadin anticoagulation with BIVADS by means of appropriate point-of-care tests now available, such as HDR slope and heparin concentration, as well as sensitive markers for excessive coagulation and fibrinolysis activation that allow more accurate assessment of the coagulation system and identification of patients at risk, and to evaluate alternate forms of antithrombotic therapy such as reversible, specific inhibition of thrombin and platelets or heparin-bound extracorporeal circuits.

\section{REFERENCES}

1. Bartlett RH. Extracorporeal life support for cardiopulmonary failure. Curr Probl Surg 1990;27:621-705.

2. Despotis GJ, Summerfield AL, Joist JH, et al. Comparison of activated coagulation time and whole blood heparin measurements to laboratory plasma anti-Xa heparin concentration in cardiac surgical patients. J Thorac Cardiovasc Surg 1994;108: 1076-82.

3. Slaughter TF, Lebleu TH, Douglas JM, et al. Characterization of prothrombin activation during cardiac surgery by hemostatic molecular markers. Anesthesiology 1994;80:520-6.

4. Esposito RA, Culliford AT, Colvin SB, Thomas SJ, Lackner $\mathrm{H}$, Spencer FC. Heparin resistance during cardiopulmonary bypass: the role of heparin pretreatment. J Thorac Cardiovasc Surg 1983;85:346-53.

5. Yamamoto K, Ikeda U, Furuhashi K, Irokawa M, Nakayama $\mathrm{T}$, Shimada $\mathbf{K}$. The coagulation system is activated in idiopathic cardiomyopathy. J Am Coll Cardiol 1995;25:1634-40. 